\title{
Estudio Morfométrico Comparativo de la Corteza Cerebelosa Humana en Dos Grupos Etarios
}

\author{
Comparative Morphometric Study of Human Cerebellar Cortex in Two Age Groups
}

Storniolo Squintone A.; Guerini, J. C.; Fonseca, I. B.; Samar, M. E. \& Spitale, L. S.

STORNIOLO SQUINTONE, A.; GUERINI, J. C.; FONSECA, I. B.; SAMAR, M. E. \& SPITALE, L. S. Estudio morfométrico comparativo de la corteza cerebelosa humana en dos grupos etarios. Int. J. Morphol., 30(3):825-828, 2012.

RESUMEN: Histológicamente la corteza del cerebelo humano adulto presenta tres capas constitutivas; la capa molecular, la hilera de los cuerpos de las células de Purkinje y la capa granulosa interna. La sustancia cortical del cerebelo de los embriones de mamífero, así como la de los jóvenes, muestran una capa granular externa. Nuestro objetivo es documentar las diferencias morfológicas entre las capas de la corteza cerebelosa adulta y joven. Se realizaron estudios morfométricos microscópicos en 20 cerebelos de autopsias. Los casos se dividieron en dos grupos, adultos y niños menores de 1 año. Se realizaron cortes en parafina, coloreados con hematoxilina y eosina. La corteza del cerebelo adulto presentó diferencias morfológicas con la de los recién nacidos. En el cerebelo adulto presenta tres capas constitutivas, mientras que en el recién nacido presenta una cuarta capa, la granulosa externa.

PALABRAS CLAVE: Cerebelo; Corteza; Capas; Adultos; Niños.

\section{INTRODUCCIÓN}

Histológicamente en la corteza del cerebelo humano adulto se diferencian netamente tres zonas desde la periferia al centro: molecular, de Purkinje y granulosa (Ramón y Cajal, 1890; Young \& Heath, 2000; Estrada Flores \& Uribe Aranzabal, 2002; Mills, 2007; Samar \& Ávila, 2010).

La capa molecular (CM) se ubica por debajo de la piamadre y mide entre $200-400 \mathrm{~mm}$. Está formada por neuronas bastante pequeñas, las células estrelladas superficiales externas y las células en cesto o estrelladas profundas. La capa de células de Purkinje (CCP) se caracteriza por presentar neuronas de gran tamaño con cuerpos celulares con una típica forma de pera o gota. En el individuo adulto miden de 50 a $100 \mu \mathrm{m}$ y proyectan sus ramificaciones dendríticas hacia la capa molecular (Young \& Heath; Staff, 2002; Mills). En la capa granulosa (CG) se observan abundantes neuronas cuyos cuerpos celulares se ubican muy próximos entre sí dando un aspecto de granos. Estas neuronas o granos del cerebelo miden entre 4 y $5 \mu \mathrm{m}$ y se sitúan entre las neuronas de Golgi tipo II.

La sustancia cortical del cerebelo de los embriones de mamíferos, así como la de los jóvenes, muestra otra capa localizada por fuera de la capa molecular y por debajo de la piamadre. Ésta es llamada por algunos autores capa granulosa superficial de Oversteiner, capa de los gránulos superficiales, o simplemente capa granulosa externa (CGE). Se halla constituida por varias hileras de células primitivas, pequeñas y poliédricas. Estas células posteriormente migran hacia la profundidad, incorporándose a la capa granulosa del cerebelo del adulto (Ramón y Cajal; Larsell \& Jansen, 1972; Young \& Heath; Staff).

El cerebelo deriva embriológicamente del rombencéfalo. Entre la $5^{\circ}$ y $6^{\circ}$ semana del desarrollo algunos neuroblastos de las placas alares del rombencéfalo migran a la región dorsolateral de la vesícula y forman los labios rómbicos (uno a cada lado). Inicialmente se proyectan desde la región dorsal del metencéfalo hacia el interior del IV ventrículo, pero posteriormente crecen y se fusionan en el plano mediano posterior. Los neuroblastos de los labios rómbicos se separan en dos capas proliferativas: externa e interna. A partir de estas estructuras embrionarias se origina la corteza cerebelosa definitiva, según la siguiente disposición: Algunos neuroblastos de la capa proliferativa interna migran hacia la externa y se ubican exactamente debajo de ella. Esta migración da origen a las células de Purkinje y de Golgi. Las células de la capa proliferativa in- 
terna no migran, quedando en la profundidad de los labios rómbicos y se diferencian en los cuatro núcleos basales del cerebelo. Posteriormente, la capa proliferativa externa se diferencia en granulosa externa (o transitoria), y partir de ésta algunos neuroblastos migran hacia el interior y se ubican debajo de las células de Purkinje y Golgi para formar a la capa granulosa definitiva. El mecanismo por el que se lleva a cabo este desplazamiento no está claro.

Las células de la capa proliferativa externa que no migran hacia adentro se diferencian en células que forman la capa molecular de la corteza cerebelosa. La capa germinal externa experimenta tres oleadas de proliferación para originar sucesivamente las tres poblaciones de neuroblastos de la corteza cerebelosa: los de las células en cesto, de los granos y de las células estrelladas (Larsell \& Jansen).

No se sabe con exactitud el tiempo necesario para que este proceso finalice. Ramón y Cajal lo menciona como "semanas posteriores al nacimiento" en tanto que otros autores consideran un período de hasta un año (Ramón y Cajal; Mills).

Basándonos en lo relatado nuestro objetivo es documentar las diferencias morfológicas entre las capas de la corteza cerebelosa adulta y joven, y realizar un estudio morfométrico de las mismas para documentar la progresiva disminución del espesor de la CGE.

\section{MATERIAL Y METODO}

Se realizaron estudios morfométricos en 20 cerebelos provenientes de autopsias, correspondientes al Instituto de Medicina Forense de la ciudad de Córdoba (Argentina) entre los años 2008/2009.

El único parámetro de selección fue la edad de los fallecidos. Se dividieron a los mismos en dos grupos; adultos (10 casos) y niños menores de 1 año (10 casos).

En cortes histológicos del material incluido en parafina y coloreados con hematoxilina y eosina (H\&E) se midió el espesor de la corteza cerebelosa. Para ello se empleó un ocular micrometrado Leitz $®$, calibrado con un portaobjeto micrometrado; se midió el espesor cortical parcial desde la capa de células de Purkinje hasta la capa molecular en los cerebelos de adultos, y hasta la capa granulosa externa en los niños, en tres campos microscópicos diferentes, con objetivo $10 \mathrm{X}$.

Se obtuvieron mediciones del soma y del núcleo de las células de Purkinje. Para documentar la disminución progresiva de la capa granulosa externa a medida que pasan los meses se recolectaron nuevos casos correspondientes a edades progresivas (recién nacido a término, 5 días, 15 días, y uno a 12 meses).

En todos los casos se hicieron mediciones de la capa granulosa externa en tres campos microscópicos diferentes, usando objetivo de $40 \mathrm{X}$.

\section{RESULTADOS}

A partir de las mediciones realizadas, se observó que el espesor de la corteza cerebelosa era significativamente mayor en los cerebelos adultos (Fig. 1). El soma de las células de Purkinje resultó más grande en los especimenes de adultos, con un promedio de $32,54 \mathrm{~mm}$ (Fig. 2).

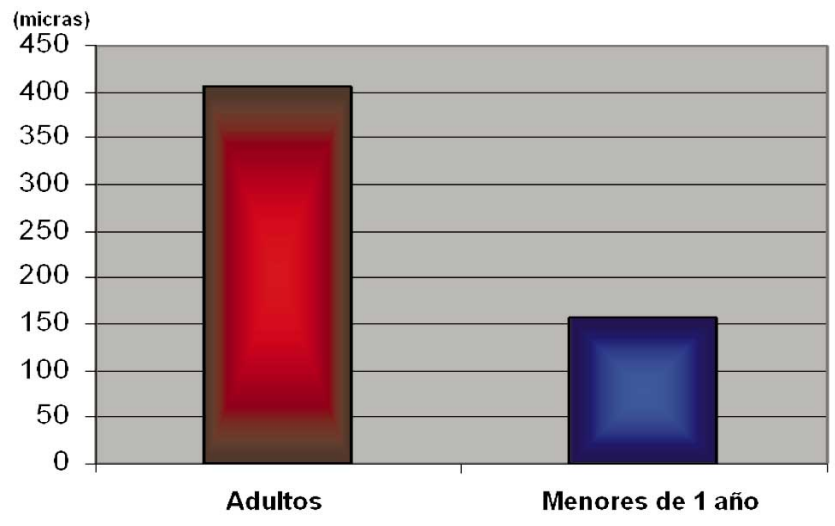

Fig. 1. Espesor promedio de las capas de la corteza cerebelosa.

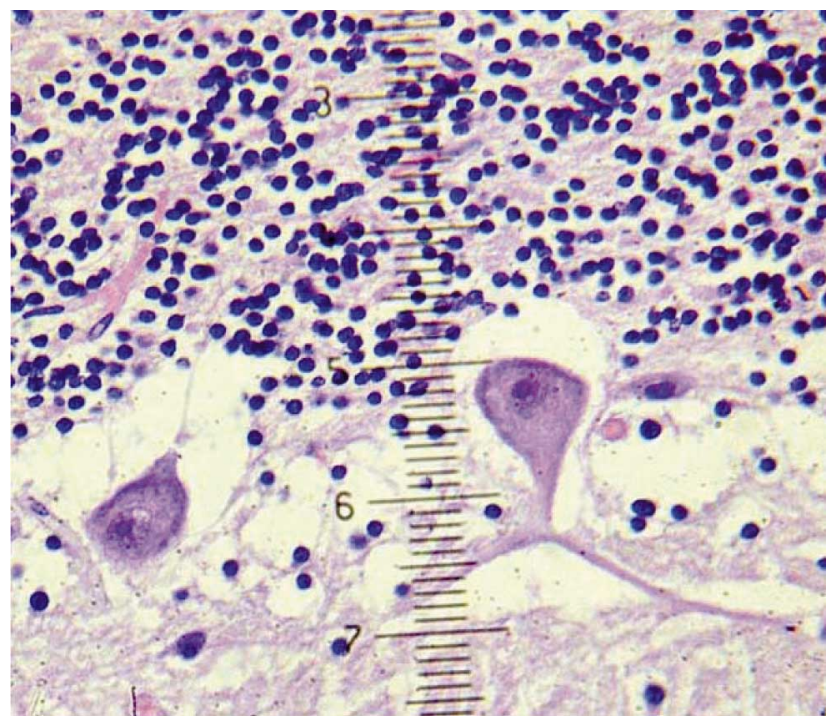

Fig. 2 se observa el proceso de medición de una célula de Purkinje. En este caso, el diámetro mayor es de $51 \mathrm{~mm}$. H\&E 40 X. 
En el grupo de menores de un año, el espesor de la corteza cerebelosa disminuía progresivamente a medida que nos acercábamos al año, no pudiéndose detectar a los 12 meses (Figs. 3 y 4). El momento exacto en el cual esta capa desaparece es variable, ya que en un caso de 7 meses de edad la corteza cerebelosa no presentaba granulosa externa, y en otros casos de 9 y 10 meses esta capa estaba presente pero su espesor estaba muy adelgazado.

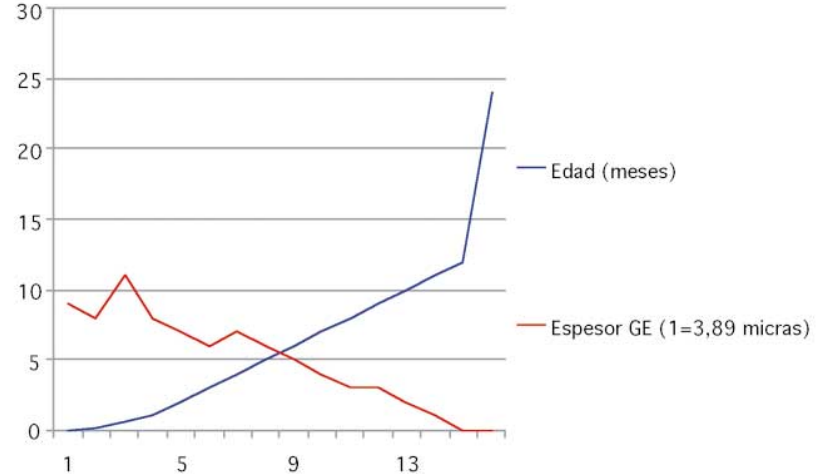

Fig. 3 Relación entre la edad y el espesor de la capa granulosa externa (GE) en el grupo de menores de un año.
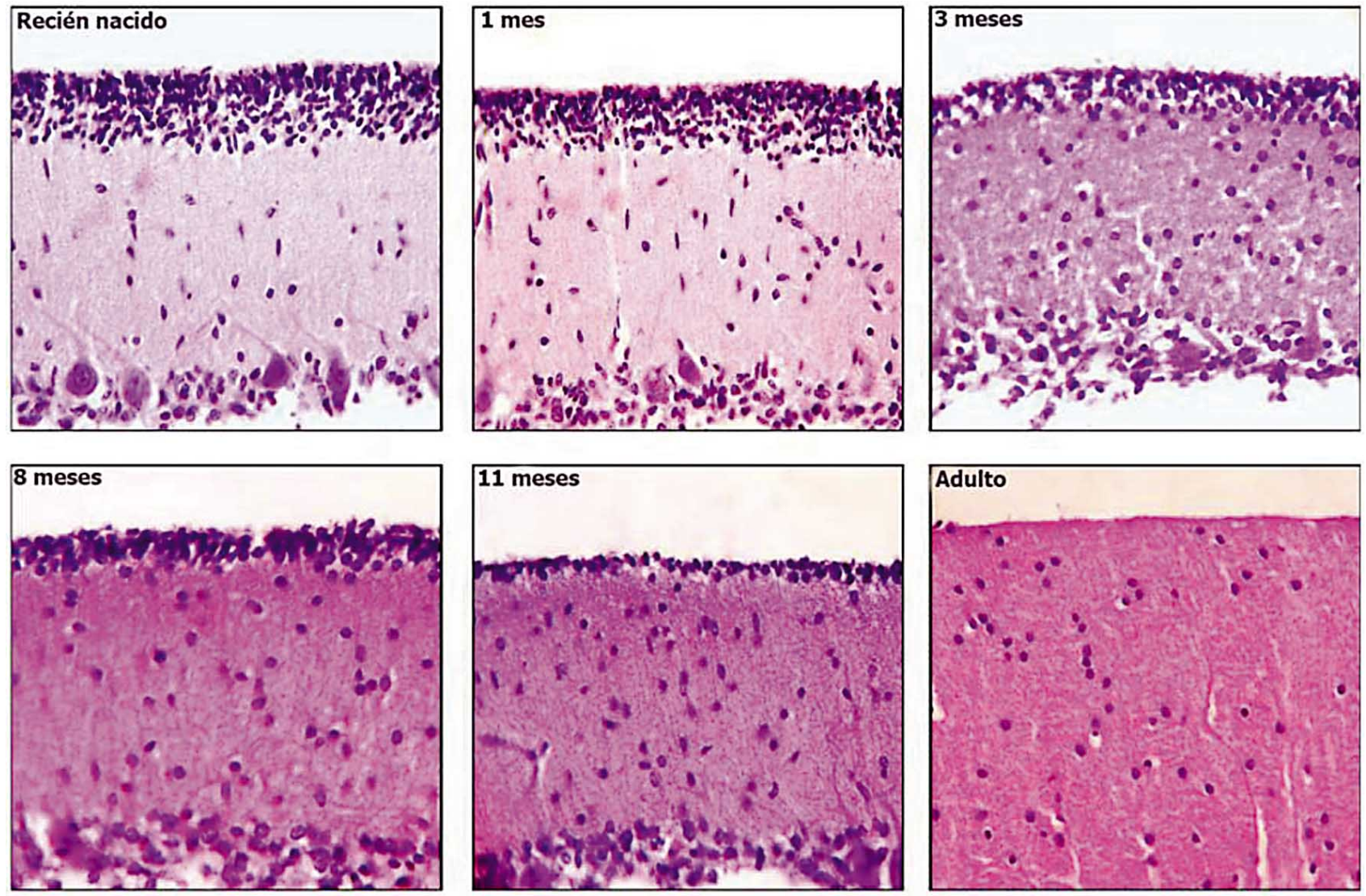

Fig. 4. Secuencia comparativa entre la edad y el espesor de la capa granulosa externa (GE) de la corteza cerebelosa.

\section{DISCUSION}

La corteza del cerebelo humano presenta un desarrollo embriológico complejo. En estadios tempranos se forma una capa de células denominada CGE, que al proliferar da origen a las células de las otras capas constitutivas del órgano (Ramón y Cajal; Larsell \& Jansen; Young \& Heath; Staff).
La CGE descripta ya por Ramón y Cajal como zona de los gránulos superficiales, está presente en el momento del nacimiento formando la capa cortical más externa (Ramón y Cajal; Mills). Con el transcurso del tiempo la misma desaparece y se cree que sus células se incorporan 
progresivamente en las restantes capas definitivas de la corteza cerebelosa.

Nuestras observaciones fueron coincidentes con las escasas descripciones en la literatura. Esta cuarta capa está constituida por corpúsculos o células inmaduras con núcleos hipercromáticos, esféricos y pequeños.

Al hacer las mediciones de la misma en el grupo de individuos menores de un año, comprobamos que esta capa disminuye de espesor con el transcurso de los meses, aunque no pudimos determinar con exactitud el momento en el que desaparece, ya que según nuestros hallazgos y los de la bibliografía consultada es variable. Sin embargo, a los 12 meses ninguno de los casos analizados presentaba la capa granulosa externa. Por lo expuesto, se concluye que la corteza del cerebelo adulto presenta diferencias morfológicas con la corteza del recién nacido.

STORNIOLO SQUINTONE, A.; GUERINI, J. C.; FONSECA, I. B.; SAMAR, M. E. \& SPITALE, L. S. Comparative morphometric study of human cerebellar cortex in two age groups. Int. J. Morphol., 30(3):825-828, 2012.

SUMMARY: Histologically, the adult human cerebellar cortex has three constituent layers, the molecular layer, the row of bodies of Purkinje cells and internal granular layer. The cortex of the cerebellum of mammalian embryos, as well as youth, show external granular layer. Our goal is to document morphological differences between the layers of the cerebellar cortex adult and young. Microscopic morphometric studies were performed in 20 cerebellum autopsied. The cases were divided into two groups, adults and children under 1 year. Paraffin sections were performed, stained with hematoxylin and eosin. The cortex of adult cerebellum showed morphological differences of the newborn. In the adult cerebellum has three constituent layers, whereas in the newborn has a fourth layer, the external granular.

KEY WORDS: Cerebellum; Cortex; Layers; Adults; Children.

\section{REFERENCIAS BIBLIOGRÁFICAS}

Estrada Flores, E. \& Uribe Aranzabal, M. C. Atlas de histología de vertebrados. México, Ed. Univ. Autónoma de Mexico, 2002. pp.189.

Larsell, O. \& Jansen, J. The comparative anatomy and histology of the cerebellum. The human cerebellum, cerebellar connections, and cerebellar cortex. Minneapolis. Ed. University of Minnesota Press, 1972.

Mills, S. E. Histology for Pathologists. $3^{\text {rd }}$ ed. Philadelphia, Lippincott Williams \& Wilkins, 2007.

Ramón y Cajal, S. Trabajos Escogidos. Sobre ciertos elementos bipolares del cerebelo joven y algunos detalles más acerca del crecimiento y evolución de las fibras cerebelosas. Barcelona, Antoni Bosch, 1980. pp.517-37.

Samar, M. E. \& Ávila, R. E. Histología humana clínicamente orientada: Tejidos y sistemas. $3^{\mathrm{a}}$ ed. Córdoba, Ed. SeisC, 2010.

Staff, VV. Atlas de RM del encefalo fetal: guia de interpretacion de las imágenes normales. $4^{\text {ta }}$ ed. Barcelona, Elsevier, 2002. pp.32.

Young, B. \& Heath, J. W. Wheater's Histología Funcional. $4^{\mathrm{a}}$ ed, Madrid, Harcourt Churchill Livingstone, 2000. pp.376.
Dirección de correspondencia:

Dra. María Elena Samar

II Cátedra de Patología y II Cátedra de Biología Celular, Histología y Embriología

Facultad de Ciencias Médicas

Universidad Nacional de Córdoba

Córdoba

ARGENTINA

Email: avilainfo@yahoo.com.ar

Recibido : 07-09-2012

Aceptado: 13-04-2012 